\title{
Variation of Bacterial and Archaeal Community Structures in a Full-Scale Constructed Wetlands for Wastewater Treatment
}

\author{
Xiu-lu Lang, Xiang Chen $(\mathbb{D}$, Ai-ling Xu, Zhi-wen Song $(\mathbb{D}$, Xin Wang, and He-bing Wang $(\mathbb{D}$ \\ School of Environmental and Municipal Engineering, Qingdao University of Technology, Qingdao 266033, China \\ Correspondence should be addressed to Zhi-wen Song; sszzww1015@sohu.com
}

Received 4 May 2018; Accepted 22 July 2018; Published 16 October 2018

Academic Editor: Jin Li

Copyright (C) 2018 Xiu-lu Lang et al. This is an open access article distributed under the Creative Commons Attribution License, which permits unrestricted use, distribution, and reproduction in any medium, provided the original work is properly cited.

\begin{abstract}
Microorganisms play important roles in the reduction of organic and inorganic pollutants in constructed wetlands used for the treatment of wastewater. However, the diversity and structure of microbial community in constructed wetland system remain poorly known. In this study, the Illumina MiSeq Sequencing of $16 S$ rDNA was used to analyze the bacterial and archaeal microbial community structures of soil and water in a free surface flow constructed wetland, and the differences of bacterial communities and archaeal compositions between soil and water were compared. The results showed that the Proteobacteria were the dominant bacteria, making up 35.38\% 48.66\% relative abundance. Euryarchaeotic were the absolute dominant archaea in the influent sample with the relative abundance of 93.29\%, while Thaumarchaeota showed dominance in the other three samples, making up 50.58\% 75.70\%. The relative abundances of different species showed great changes in bacteria and archaea, and the number of dominant species in bacteria was much higher than that in archaea. Compared to archaea, the community compositions of bacteria were more abundant and the changes were more significant. Meanwhile, bacteria and archaea had large differences in compositions between water and soil. The microbial richness in water was significantly higher than that in soil. Simultaneously, soil had a significant enrichment effect on some microbial flora.
\end{abstract}

\section{Introduction}

As a new type of sewage treatment system, constructed wetlands have gradually entered the field of vision. Constructed wetlands for wastewater treatment were widely used in developed countries, such as the United States and Germany, because of its low costs, good removal rates for organic substances and also for nutrients (N, P), and higher surface water quality [1]. Shandong Province had built many constructed wetlands which occupied $7.6 \%$ of the land [2] and mainly distributed in Nansi Lake and Dongping Lake [3]. The constructed wetlands could remove pollutants through providing habitats for microbes to stimulate their activities [4]; therefore, microorganisms were particularly important in the reduction of organic and inorganic pollutants in constructed wetlands. Due to the uncertainty and variability of the distribution of microbial community structure in constructed wetlands, it had aroused the interest and attention of scholars.
At present, extensive researches have been conducted on microbial community structure of sewage treatment systems [5-7]. Recently, with the development of highthroughput sequencing technology, it has also been widely used in environmental samples, such as the bacterial community structures in airborne [8] and water [9] and the archaeal community structures in soil [10], even in the sludge of wastewater treatment [11]. However, the above studies have rarely analyzed the bacterial and archaeal community structures of the same samples at the same time. Similar studies also show significant differences due to environmental differences in the study sites.

Therefore, in this study, the water and soil samples, collected from a free surface flow constructed wetland, were assessed by Illumina MiSeq high-throughput method, the objective was to investigate the microbial community structures and compare the microbial abundance differences between water and soil, including bacteria and archaea. 


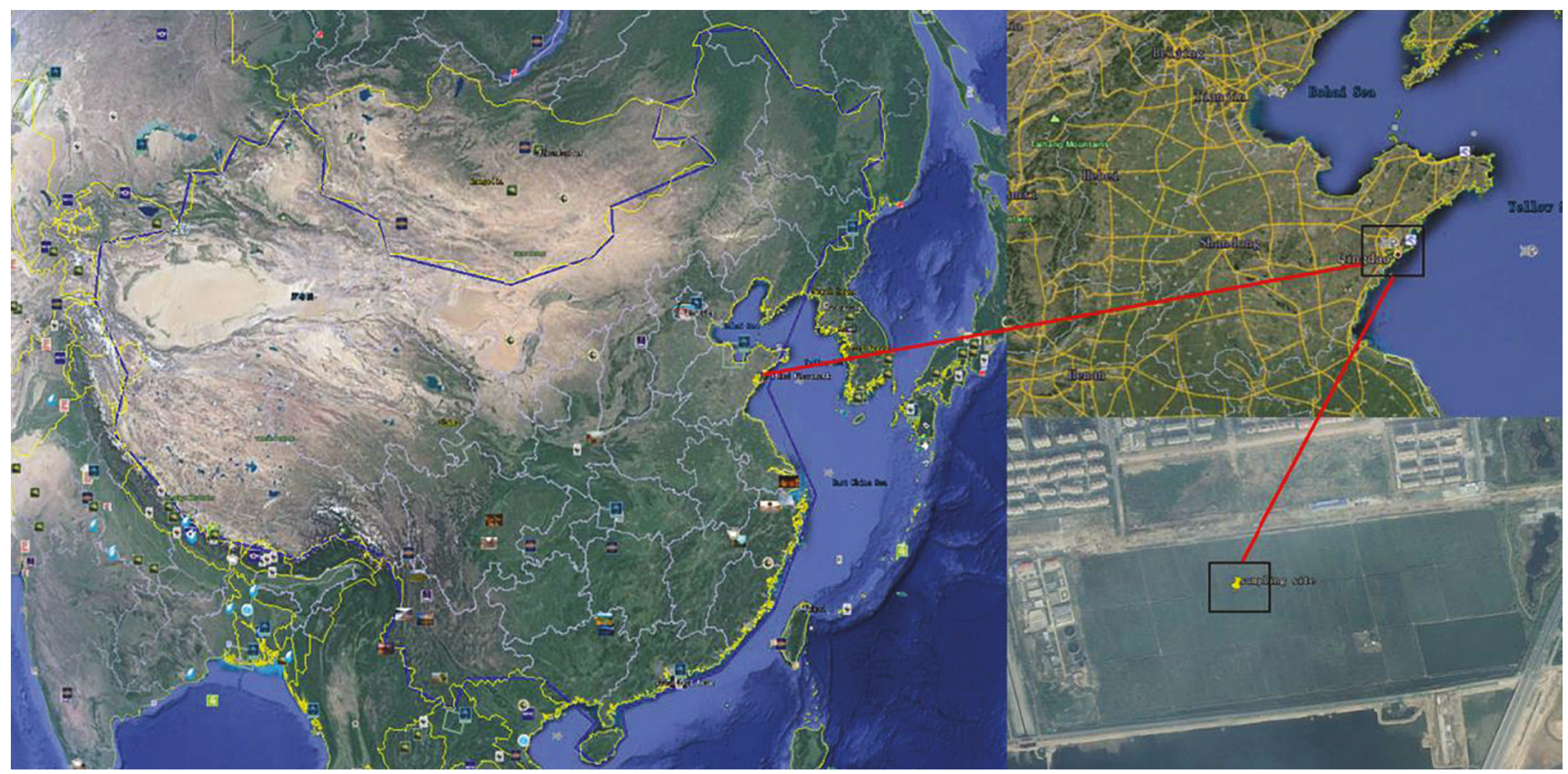

FIGURE 1: Map showing the location of the sampling sites in constructed wetland.

\section{Methods}

2.1. Sampling Sites. The free water surface constructed wetland, located in the interior of Huangdao District (Qingdao City, Shandong Province, China), at a latitude of $35^{\circ} 35^{\prime}$ to $36^{\circ} 08^{\prime}$ north and a longitude of $119^{\circ} 30^{\prime}$ to $120^{\circ} 11^{\prime}$ east, is a part of an integrated sewage purification system. This region has a warm temperate continental monsoon with a mean annual temperature of $12.0^{\circ} \mathrm{C}$ and a mean annual precipitation of $794 \mathrm{~mm}$. The constructed wetland wastewater treatment system had a total area of $76.7 \mathrm{hm}^{2}$ and a treatment capability of $3.0 \times 10^{4} \mathrm{~m}^{3} \cdot \mathrm{d}^{-1}$ and was surrounded by the Yellow Sea on east and south. It consisted of 99 treatment beds and received secondary unchlorinated wastewater from Jiaonan Municipal Wastewater Treatment Facility with $\mathrm{A}^{2} \mathrm{O}$ as the secondary treatment. All beds were planted with common reed (Phragmites australis) and a number of naturally germinated wetland plants (Typha orientalis, Scirpus validus, Lemna minor, etc.). To facilitate the harvest progress of above-ground biomass, sewage did not enter the constructed wetland bed from December to March of next year. In this study, two different constructed wetland treatment units with and without sewage water were selected, wet soil and dry soil from each unit, and influent and effluent from unit with sewage water were sampled in May 2017. Detailed geographic information of the sampling sites is shown in Figure 1.

2.2. Sampling Methods. $50 \mathrm{~g}$ of soil sample and $10 \mathrm{~L}$ of water sample were collected from each sample site by sterile sealed bags and sterile bottles, respectively. After removing the fine roots in soil samples, the water and soil samples were transferred to the laboratory immediately. After dewatered by centrifugation, a fraction of the soil samples were stored at $-20^{\circ} \mathrm{C}$ for molecular analysis. A part of water samples was filtered by a vacuum pump with 45 -mm-diameter microporous membrane, then using douching and centrifugation method carefully transferred into $2 \mathrm{~mL}$ sterile centrifuge tubes and stored at $-20^{\circ} \mathrm{C}$ until DNA extraction; meanwhile, the other part was stored at $4^{\circ} \mathrm{C}$ for chemical analysis.

2.3. DNA Extraction. Soil DNA and water DNA were extracted from $500 \mathrm{mg}$ of frozen soil and $500 \mathrm{mg}$ of filter residue, respectively, using a Soil DNA Kit (OMEGA, China) according to the manufacturer's instructions. The extracted DNA was checked using the UV/nucleic acid protein detector (IMPLEN, Germany).

2.4. Illumina MiSeq Sequencing. Targeting target sequences reflects the compositions and diversities of microbes, designing corresponding primers according to the conserved regions in the sequences and adding sample-specific barcode sequences to further amplify the variable region of the rRNA gene (single or continuous) or specific gene fragments for PCR amplification. PCR amplification products were detected by $2 \%$ agarose gel electrophoresis, and the target fragment was excised from the gel. PCR products were recovered for fluorescence quantification, according to the needs of each sample sequencing volume, and the samples were mixed in the appropriate ratio. Sequencing libraries were prepared using Illumina's TruSeq Nano DNA LT Library Prep Kit and on the machine for high-throughput sequencing.

2.5. Sequence Data Analyses. In order to integrate the original double-end sequencing data, the two-terminal sequence of FASTQ format was first screened by sliding window. The size of the window is $10 \mathrm{bp}$ and the step size is $1 \mathrm{bp}$. Starting from the first base position on the $5^{\prime}$ end, the average base mass in the window is $\geq Q 20$ (i.e., the base average measurement 
TABle 1: Physical and chemical characteristics in samples.

\begin{tabular}{lccccccc}
\hline Samples & $\begin{array}{c}\text { Total phosphorus } \\
(\mathrm{g} / \mathrm{kg})\end{array}$ & $\begin{array}{c}\text { Total nitrogen } \\
(\mathrm{g} / \mathrm{kg})\end{array}$ & $\begin{array}{c}\text { Organic matter } \\
(\mathrm{g} / \mathrm{kg})\end{array}$ & Samples & $\begin{array}{c}\text { Dissolved oxygen } \\
(\mathrm{mg} / \mathrm{L})\end{array}$ & $\begin{array}{c}\text { Ammonia nitrogen } \\
(\mathrm{mg} / \mathrm{L})\end{array}$ & $\begin{array}{c}\text { Nitrite nitrogen } \\
(\mathrm{mg} / \mathrm{L})\end{array}$ \\
\hline Dry soil & 2.66 & 22.12 & 391.61 & Influent & 8.93 & 6.05 & 1.06 \\
Wet soil & 0.38 & 7.56 & 26.75 & Effluent & 11.53 & 1.30 & 6.97 \\
\hline
\end{tabular}
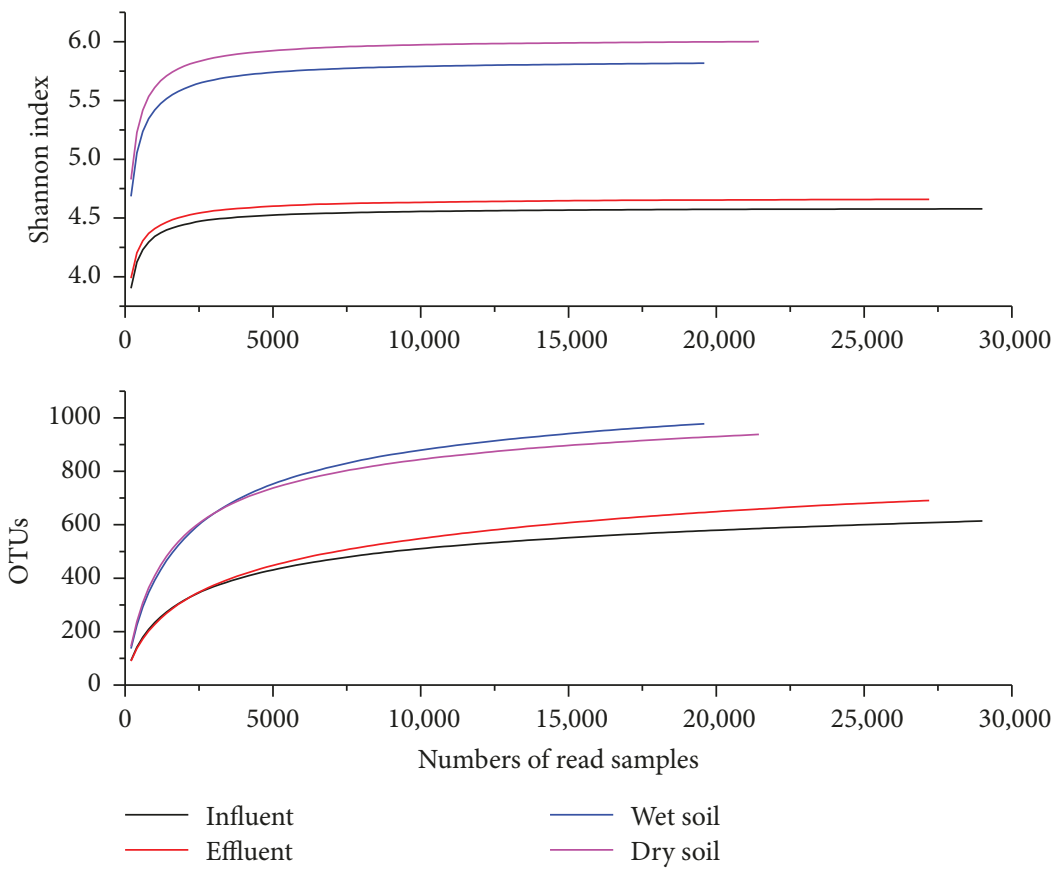

FIGURE 2: Bacterial rarefaction curves and Shannon diversity index curves.

accuracy is $\geq 99 \%$ ). From the first truncated sequences at windows, with average mass values below Q20, we requir a truncated sequence $\geq 150 \mathrm{bp}$ in length with no ambiguous base $\mathrm{N}$ allowed. Subsequently, the FLASH software [12](v1.2.7, http://ccb.jhu.edu/software/FLASH/) was used to pair the double-stranded sequences that passed the quality screening according to overlapping bases. It is required that the overlapping base length of two sequences of read 1 and read 2 be $\geq 10 \mathrm{bp}$ and the base mismatch is not allowed. Finally, based on the index information (i.e., barcode sequence, for the beginning of the sequence used to identify a small base sequence) corresponding to each sample, the connected sequence identification is assigned to the corresponding sample (requires index sequence exactly match), to obtain a valid sequence for each sample.

\section{Results}

3.1. Physical and Chemical Characteristics of Soil and Water in Constructed Wetlands. The results of soil and water basic properties were listed in Table 1. All the chemical indicators of wet soil were far below the dry soil, especially content of organic matter, and dry soil was about 15 times more than wet soil. The constructed wetlands had a very good purification effect; ammonia nitrogen and nitrite nitrogen in effluent decreased obviously. Simultaneously, the content of dissolved oxygen also improved.

\subsection{Bacterial Community Structures of Soil and Water in Constructed Wetlands}

3.2.1. Bacterial Alpha Diversity Analysis. Rarefaction curves of the four samples were shown in Figure 2. The rarefaction curves and Shannon diversity index curves clearly revealed that the bacterial community structures of soil samples were considerably higher than those in water samples. Two kinds of curves tended to be gentle, suggesting that the sequencing results had been enough to reflect the diversity of the current sample, and increasing the depth of sequencing could not detect more new OUTs. The sequencing results could basically reflect the microbial community structures of four samples.

A total of 29,000,27,204, 19,597, and 21,439 trimmed reads for samples influent, effluent, wet soil, and dry soil were obtained, respectively, after the removal of unqualified reads (Table 2). ACE estimator [13] and Chaol estimator [14] were used to estimate the number of species actually present in the community. The greater Chaol estimator, the higher richness of the community, and so was the ACE estimator. The community richness in soil samples was much higher than that in water samples, showing microbes were more likely 
TABLE 2: Bacterial alpha diversity indices of four samples.

\begin{tabular}{ccccccc}
\hline Samples & Reads & OTUs & ACE & Chao1 & Shannon & Simpson \\
\hline Influent & 29,000 & 614 & 676.31 & 707.02 & 4.58 & 0.05 \\
Effluent & 27,204 & 691 & 792.39 & 783.76 & 4.66 & 0.03 \\
Wet soil & 19,597 & 978 & 1051.89 & 1080.43 & 5.82 & 0.01 \\
Dry soil & 21,439 & 938 & 1002.35 & 1019.01 & 6.00 & 0.01 \\
\hline
\end{tabular}

to attach to solid particles. Shannon diversity index [15] and Simpson index [16] were both the commonly used index for evaluating community diversity; the higher Shannon index and the lower Simpson diversity index could explain the higher community diversity. The community diversity in dry soil sample was the highest in this study, while that in influent sample was the lowest. Simpson index was more sensitive to uniformity and dominant OTUs in the community, and it demonstrated a high degree of uniformity in four samples.

\subsubsection{Bacterial Community Structures of Soil and Water in} Constructed Wetlands. Bacterial sequences in the four samples were classified into taxonomic classes using the default settings of the mothur platform. A total of 29 bacterial phyla were found in this study. The total phylum numbers in influent, effluent, wet soil, and dry soil were 22, 23, 23, and 23, respectively. Four samples were similar in the number of phyla levels, but quite different in compositions, and the detailed relative abundances were shown in Figure 3. In the four samples, Proteobacteria, Firmicutes, Actinobacteria, Bacteroidetes, Cyanobacteria, and Chloroflexi were the most common bacterial phyla with a high relative abundance, while the proportion of the other phyla were very low. Proteobacteria were the most dominant phylum in the four samples with the relative abundance of $35.38 \% \sim 48.66 \%$. Firmicutes in influent sample (30.12\%) and Bacteroides in effluent (30.03\%) and wet soil (20.05\%) samples also showed in absolute superiority. Different from the other three samples, the proportion of Chloroflexi in dry soil was high, accounting for $18.96 \%$. The community structures of the two water samples were more similar, and so were the two soil samples. Most bacterial phyla were found in all 4 samples, such as Verrucomicrobia, Planctomycetes, and Ignavibacteriae. However, Aquificae, Lentisphaerae, and Synergistetes were emerged only in the water samples, while Thermotogae, Deferribacteres, Calditrichaeota, and Armatimonadetes existed only in the soil samples. Tenericutes and Fusobacteria were detected in all samples except dry soil, while Balneolaeota were emerged only in the effluent with a very low relative abundance. It is worth noting that Euryarchaeota, which belonged to archaea, were also detected in this bacterial sequencing.

The distribution characteristics of classes were analyzed, and the results were shown in Figure 4. A total of 68 bacterial classes were found in this study. The total class numbers in influent, effluent, wet soil, and dry soil were $44,47,55$, and 53, respectively. The abundance distributions of Alphaproteobacteria, Sphingobacteriia, and Gammaproteobacteria in the four samples were relative average, while the relative

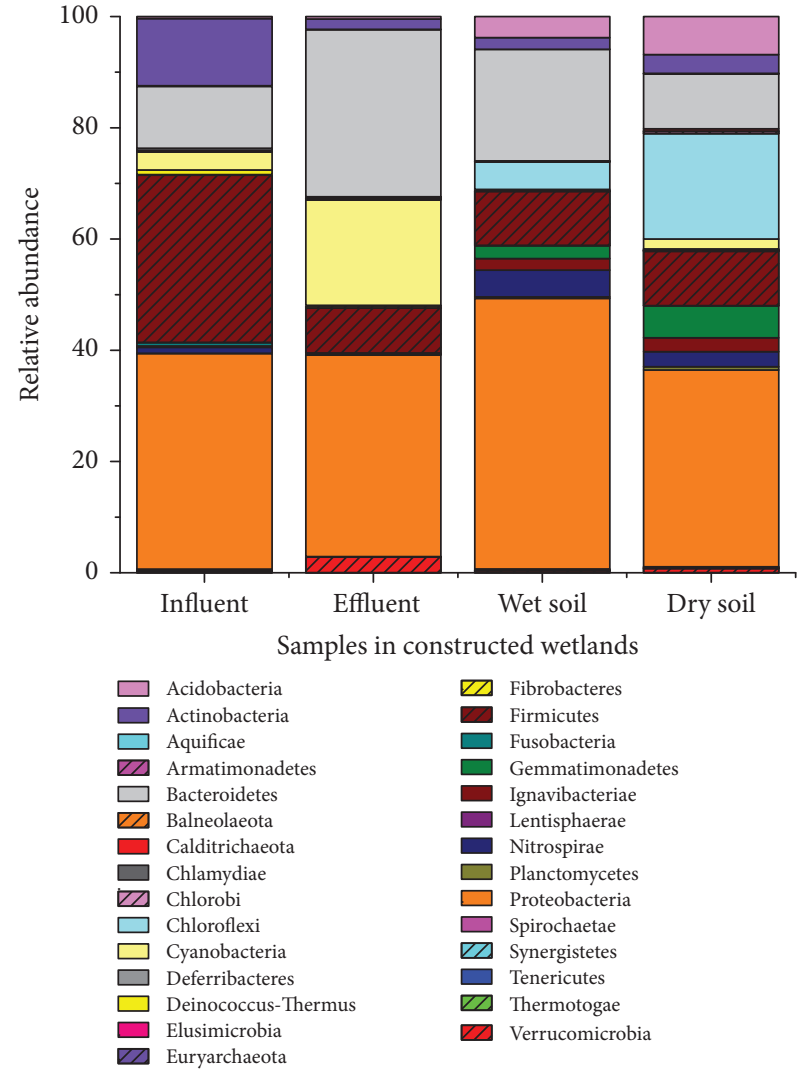

FIgURE 3: Bacterial relative abundance of four samples in phyla in constructed wetlands.

abundances of the other classes were quite different. Clostridia, Actinobacteria, and Epsilonproteobacteria were the dominant classes in the influent with the relative abundance of $26.91 \%, 11.96 \%$, and $7.76 \%$, respectively, while they did not exceed $3 \%$ in the other three samples; however, the relative abundances of Fusobacteriia were obviously higher in influent than the other three samples. The relative abundances of Fimbriimonadia and Fibrobacteria in wet soil and Ignavibacteria in dry soil were much higher than the other three samples. Cyanobacteria and Flavobacteriia were most frequently detected in effluent accounting for $18.84 \%$ and $18.02 \%$, respectively, while they showed a lower relative abundance in the other three samples. The relative abundances of Betaproteobacteria were less than $10 \%$ in the dry soil, while it showed advantage in the other three samples accounting for $18.15 \%$ 20.9\%. Coriobacteriia, Chloroflexia, etc., a total of 19 classes, were only detected in the soil samples, and among them, there were 3 classes only in wet soil and 5 classes in dry soil. Deltaproteobacteria, Erysipelotrichia, etc., a total of 8 classes, were only detected in the water samples and 3 classes emerged only in effluent.

Due to the huge amount of data, the dominant genera, with relative abundances over $1 \%$, were listed in Table 3. A total of 40 bacterial genera were found. The total genus numbers in influent, effluent, wet soil, and dry soil were $28,33,28$, and 22, respectively. In influent sample, in addition to $\mathrm{Myco}$ bacterium and Rhodoferax, the other 10 dominant genera in the other three samples, the relative abundances were all less 


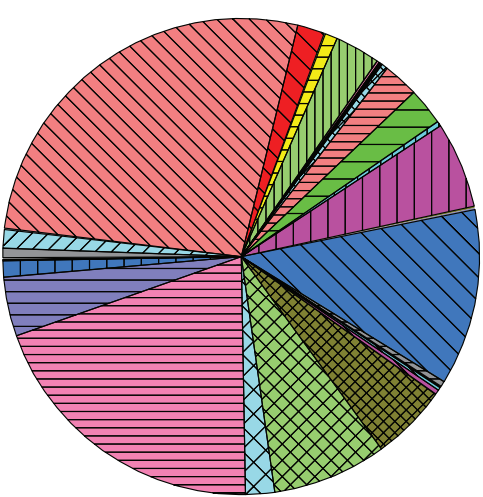

Influent

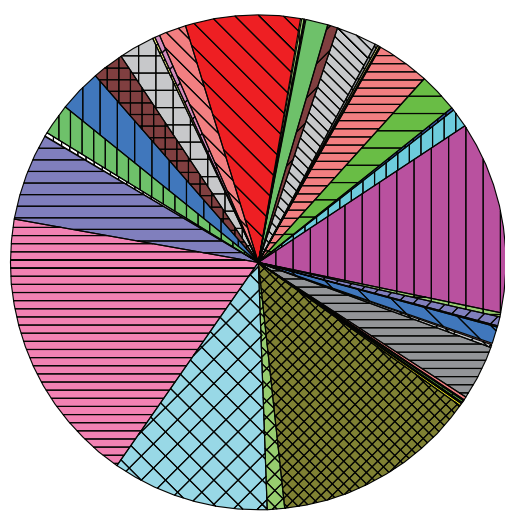

Wet soil

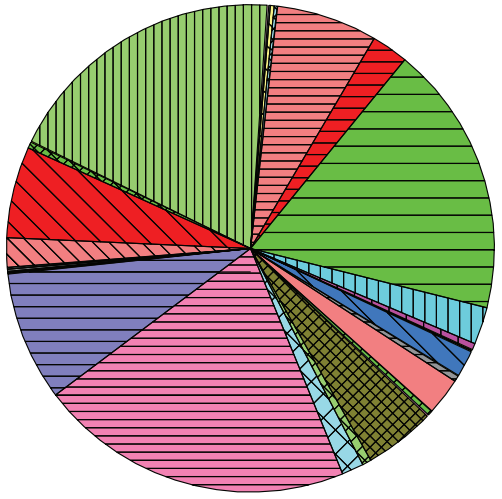

Effluent

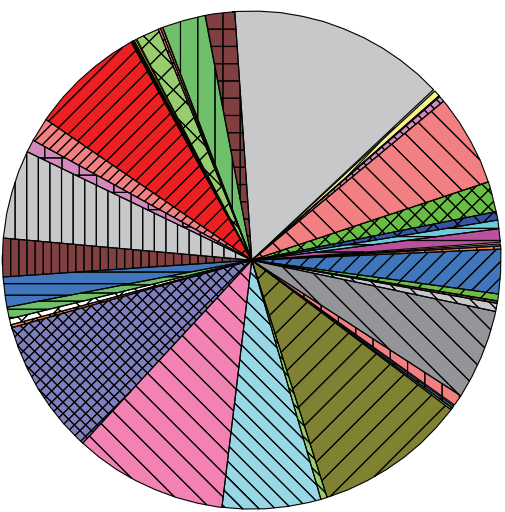

Dry soil

AIV Calditrichae

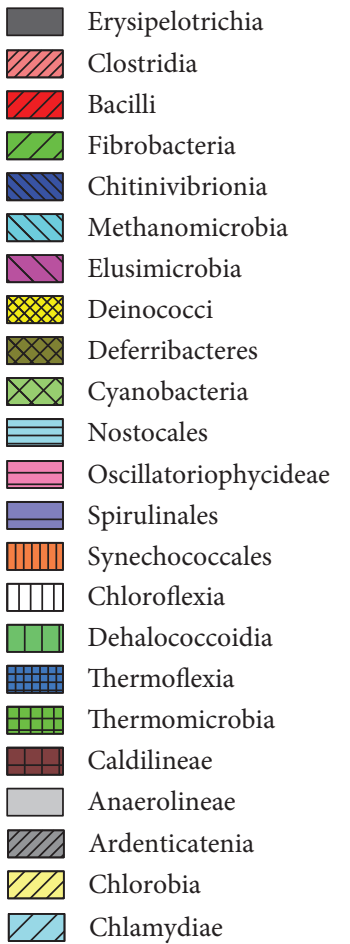

Sphingobacteriia

Saprospiria

Flavobacteriia

X Chitinophagia

Eytophagia

Bacteroidia

$\rightleftarrows$ Fimbriimonadia

IIIII Aquificales

पIII Nitriliruptoria

$\square$ Thermoleophilia

巴且 Streptosporangiales

其田 Micrococcales

11 Bifidobacteriales

$\square$ Corynebacteriales

VIIA Coriobacteriia

DID Actinobacteria

$\measuredangle Z$ Acidobacteriales

IIV Acidimicrobiia

NIV Blastocatellia

Acidobacteria $\triangle Z$ Chlamydiae

世畊 Negativicutes

$\#$ Hydrogenispora

Figure 4: Bacterial relative abundance of four samples in classes in constructed wetlands. 
TABLE 3: The bacterial dominant genera in four samples in constructed wetlands.

\begin{tabular}{|c|c|c|c|c|}
\hline $\begin{array}{l}\text { Name of similar } \\
\text { genera }\end{array}$ & $\begin{array}{c}\text { Influent } \\
(\%)\end{array}$ & $\begin{array}{c}\text { Effluent } \\
(\%)\end{array}$ & $\begin{array}{c}\text { Wet soil } \\
(\%)\end{array}$ & $\begin{array}{c}\text { Dry soil } \\
(\%)\end{array}$ \\
\hline Aliterella & - & 1.39 & 0.01 & - \\
\hline Alkaliphilus & 20.67 & 0.36 & 0.01 & - \\
\hline Arcobacter & 4.74 & 0.24 & 0.34 & - \\
\hline Bacillus & 0.12 & 1.46 & 1.60 & 1.69 \\
\hline Calothrix & 0.71 & 12.92 & 0.01 & 0.49 \\
\hline Curvibacter & 1.33 & 0.21 & 0.01 & 0.01 \\
\hline Dechloromonas & 3.03 & 0.13 & 0.29 & 0.05 \\
\hline Desulfobulbus & - & - & 1.05 & 0.07 \\
\hline Dysgonomonas & 1.08 & 0.05 & - & - \\
\hline Enterococcus & 0.30 & 1.61 & 1.58 & 1.48 \\
\hline Flavobacterium & 0.09 & 10.93 & 0.13 & 0.54 \\
\hline Fluviicola & 0.29 & 1.53 & 0.04 & - \\
\hline Gemmatimonas & 0.12 & 0.01 & 1.10 & 2.41 \\
\hline Gemmobacter & 0.10 & 1.18 & 0.03 & - \\
\hline Haliscomenobacter & - & 2.40 & - & - \\
\hline Herminiimonas & 4.82 & 0.33 & - & - \\
\hline Hydrogenophaga & 0.21 & 2.58 & 0.18 & 0.04 \\
\hline Janthinobacterium & 0.17 & 1.85 & - & - \\
\hline Lactococcus & 0.23 & 2.26 & 3.22 & 3.11 \\
\hline Limnohabitans & 0.07 & 6.83 & - & - \\
\hline Mycobacterium & 8.33 & 1.35 & 0.10 & 0.11 \\
\hline Nordella & 1.09 & 0.21 & 0.04 & 0.03 \\
\hline Owenweeksia & - & 1.20 & - & - \\
\hline Polaribacter & - & 1.30 & - & - \\
\hline Prevotella & 1.56 & 0.15 & - & - \\
\hline Pseudomonas & 0.22 & 0.08 & 0.32 & 1.40 \\
\hline Rhodoferax & 2.97 & 4.08 & 0.96 & 0.08 \\
\hline Sediminibacterium & 0.33 & 1.03 & - & - \\
\hline Steroidobacter & 0.03 & - & 1.06 & 0.36 \\
\hline Sulfuricaulis & - & - & 0.61 & 2.00 \\
\hline Synechococcus & - & 1.60 & - & - \\
\hline Tabrizicola & 0.07 & 1.03 & 0.09 & 0.01 \\
\hline Taibaiella & - & 1.21 & 0.02 & 0.04 \\
\hline Tangfeifania & - & - & 6.71 & - \\
\hline Thermanaerothrix & - & - & 0.01 & 1.07 \\
\hline Thermodesulfovibrio & - & - & 1.19 & 0.50 \\
\hline Thiobacillus & 0.06 & 0.01 & 3.61 & 1.96 \\
\hline Thiohalobacter & - & - & 1.35 & 0.03 \\
\hline Trichococcus & 1.10 & 0.03 & - & - \\
\hline Vogesella & 1.12 & 0.03 & - & - \\
\hline
\end{tabular}

than 1\%. Haliscomenobacter, Synechococcus, Polaribacter, and Owenweeksia were emerged only in the effluent, simultaneously, and Herminiimonas, Prevotella, Vogesella, Trichococcus, and Dysgonomonas were detected only in the water samples. The quantities of dominant genera in the soil samples were lower than those of the water samples, obviously. Tangfeifania were emerged only in the wet soil, while Sulfuricaulis, Thermanaerothrix, Thermodesulfovibrio, Desulfobulbus, and Thiohalobacter were detected only in the water samples. Interestingly, the relative abundance of Alkaliphilus in influent was as high as $20.67 \%$, while the sum of all dominant genera in the dry soil was $15.12 \%$.

\subsection{Archaeal Community Structures in Constructed Wetlands}

3.3.1. Archaeal Alpha Diversity Analysis. Rarefaction curves of the four samples were shown in the Figure 5. The rarefaction curves and Shannon diversity index curves of four samples clearly revealed that the archaeal community structures of soil samples were considerably higher than those of water samples. Two kinds of curves tended to be gentle, suggesting that the sequencing results had been enough to reflect the diversity of the current sample, and increasing the depth of sequencing could not detect more new OUTs. The sequencing results could basically reflect the microbial community structures of four samples. The trend changes of rarefaction curves and Shannon diversity index curve between archaea and bacteria were exactly the same.

A total of $56,140,32,879,61,599$, and 28,301 trimmed reads for samples influent, effluent, wet soil, and dry soil were obtained, respectively, after the removal of unqualified reads (Table 4). The community richness in wet soil sample was much higher than that in the other three samples, suggesting that archaea became active under wet anoxic conditions [17]. The community diversity of archaea in wet soil sample was the highest in this study, while that in effluent sample was the lowest. The Shannon index was more sensitive to the abundance of the community and the rare OTUs, indicating that there were more unidentified species in the archaeal community. In addition to the ACE estimator and Chaol estimator in effluent and dry soil, the other alpha diversity indices were all higher than the bacterial community structures.

3.3.2. Archaeal Community Structures of Soil and Water in Constructed Wetlands. Archaeal sequences in the four samples were classified into taxonomic classes using the default settings of the Qiime platform. Unlike bacteria, the result of archaea is quite simple and the number of phyla was very low. A total of 3 archaeal phyla were found existing in all four samples, but quite different in compositions, and the detailed relative abundances were shown in Figure 6. Euryarchaeotic were the absolute dominant phylum in the influent sample with the relative abundance of $93.29 \%$, while it was no more than $15 \%$ in the other three samples. Thaumarchaeota showed dominance in the other three samples $(50.58 \% \sim 75.70 \%)$ but accounted for only $1.28 \%$ in the influent. Crenarchaeota were one of the common archaeal phyla in the soil samples with a high relative abundance $(20.86 \%$ and $33.61 \%)$, while the proportion was very low in the water samples $(0.34 \%$ and $0.61 \%)$. Simultaneously, some archaeal phyla and no blast hit sequences were also found in the samples which were classified into others. The community structures of the two soil samples were more similar, while the structures of two water samples were quite different. 

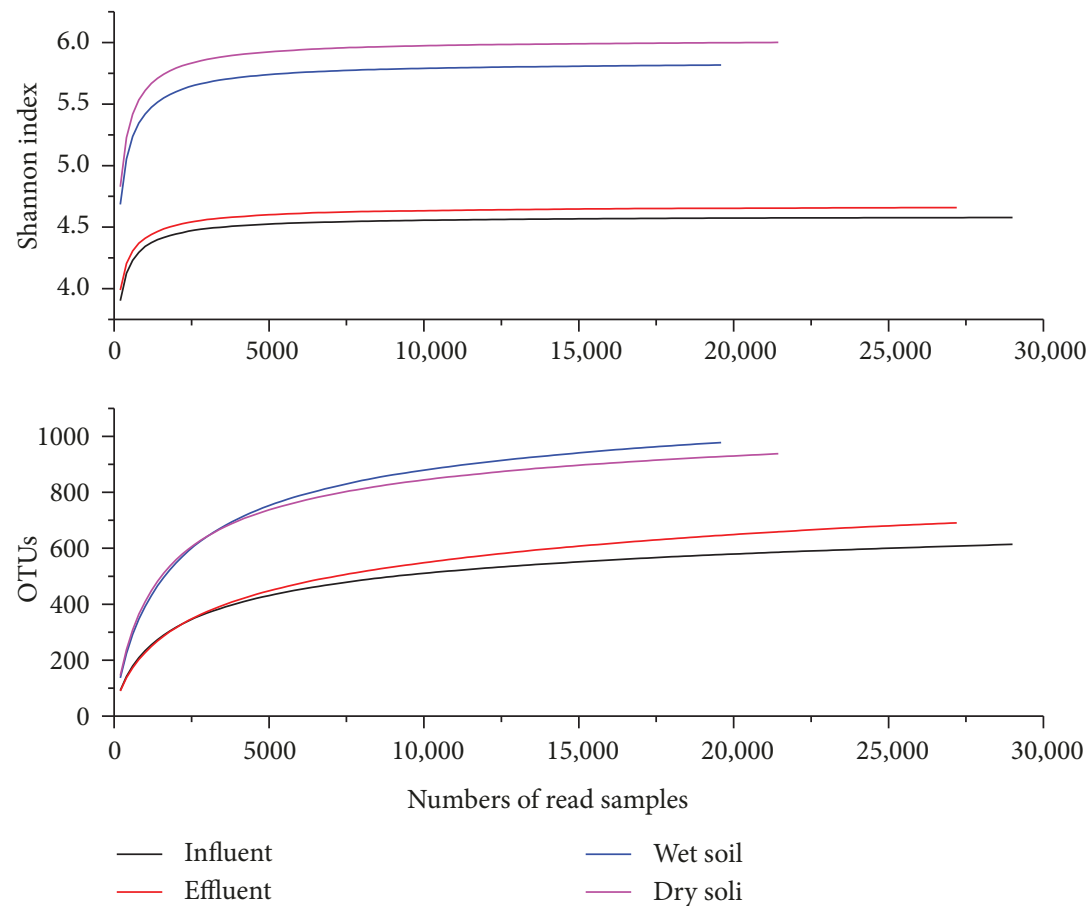

FIGURE 5: Archaeal rarefaction curves and Shannon diversity index curves.

TABLE 4: Archaeal alpha diversity indices of four samples.

\begin{tabular}{ccccccc}
\hline Samples & Reads & OTUs & ACE & Chao1 & Shannon & Simpson \\
\hline Influent & 56,140 & 2185 & 850.94 & 817.04 & 6.23 & 0.96 \\
Effluent & 32,879 & 1752 & 727.75 & 714.25 & 5.61 & 0.92 \\
Wet soil & 61,599 & 3994 & 1510.08 & 1454.2 & 7.54 & 0.98 \\
Dry soil & 28,301 & 1546 & 773.00 & 773.00 & 6.49 & 0.97 \\
\hline
\end{tabular}

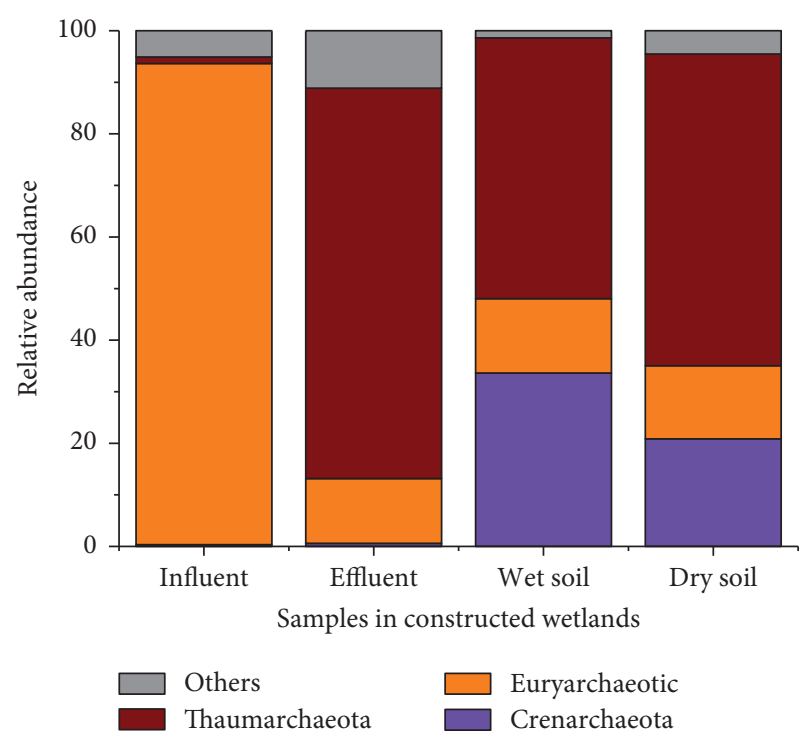

Figure 6: Archaeal relative abundance of four samples in phyla in constructed wetlands.
The distribution characteristics of classes were shown in Figure 7. A total of 11 archaeal classes were found, and the total class numbers in influent, effluent, wet soil, and dry soil all were 10 . The relative abundances of different classes were quite different. Methanomicrobia and Thermoprotei were the dominant classes in the influent and wet soil, with the relative abundances of $81.58 \%$ and $33.61 \%$, while Nitrosopumilales showed advantage in the effluent and dry soil, accounting for $75.12 \%$ and $51.51 \%$. It was worth pointing out that the relative abundances of Nitrosopumilales were high not only in the soil samples but also in the effluent $(30.44 \%)$, while it was very low in the influent, indicating that Nitrosopumilales was nonexistent in the sewage and mainly existed in the wetland matrix. Methanomicrobia had a low concentration in the other three samples, except in the influent, guessing the main source of it was the sewage treatment process. The relative abundances of Thermoprotei, Thermoplasmata, and Nitrososphaeria in soil samples were much higher than those in water samples.

Due to the huge amount of data, the dominant genera, with relative abundances over $1 \%$, were listed in Table 5. A total of 13 archaeal genera were found in this study. The archaeal dominant genera in four samples accounted for $86.83 \% \sim 95.95 \%$ in archaeal microbial communities. In influent sample, Methanosaeta and Methanocorpusculum were the dominant genera, but they had very low relative abundances in the other three samples. Except for them, the other 11 dominant genera were all less than $7 \%$. The relative abundances of Nitrososphaera, Ignisphaera, Staphylothermus, Thermodiscus, and Methanomassiliicoccus in soil samples were much higher than those in water samples. It was worth pointing out that Nitrosopumilus all had very high relative 


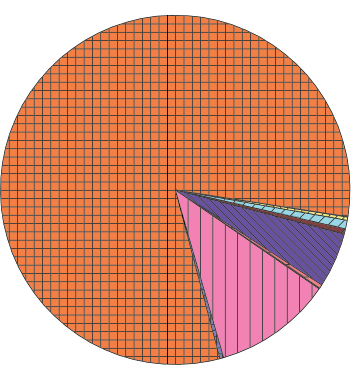

Influent

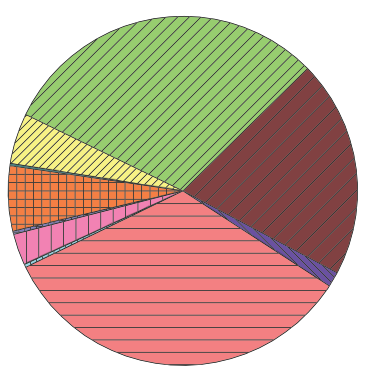

Wet soil

Thermoprotei

Archaeoglobi

|||||||| Halobacteria

पIII Methanobacteria

Methanococci

Methanomicrobia

Figure 7: Archaeal relative abundance of four samples in classes in constructed wetlands.

TABLE 5: The archaeal dominant genera in four samples in constructed wetlands.

\begin{tabular}{lcccc}
\hline Name of similar genera & $\begin{array}{c}\text { Influent } \\
(\%)\end{array}$ & $\begin{array}{c}\text { Effluent } \\
(\%)\end{array}$ & $\begin{array}{c}\text { Wet soil } \\
(\%)\end{array}$ & $\begin{array}{c}\text { Dry soil } \\
(\%)\end{array}$ \\
\hline Nitrososphaera & 0.49 & 0.57 & 20.14 & 8.93 \\
Nitrosopumilus & 0.79 & 75.12 & 30.44 & 51.51 \\
Methanomassiliicoccus & 0.24 & 0.36 & 4.48 & 8.61 \\
Methanosarcina & 2.39 & 0.02 & 2.68 & 0.37 \\
Methanomethylovorans & 1.13 & 0.33 & 0.03 & - \\
Methanosaeta & 42.44 & 3.04 & 2.16 & 0.14 \\
Methanocorpusculum & 34.42 & 5.60 & 0.12 & - \\
Methanobrevibacter & 6.29 & 0.75 & 0.44 & 0.45 \\
Methanobacterium & 3.95 & 0.41 & 1.89 & 2.53 \\
Thermodiscus & 0.24 & 0.50 & 25.53 & 14.08 \\
Staphylothermus & 0.06 & 0.05 & 1.73 & 1.89 \\
Ignisphaera & 0.02 & 0.04 & 4.58 & 3.17 \\
Desulfurococcus & 0.02 & 0.02 & 1.77 & 1.71 \\
\hline
\end{tabular}

abundances in effluent, wet soil, and dry soil samples, but less than $1 \%$ in influent sample.

\section{Discussion}

4.1. Bacterial Diversity and Community of Soil and Water in Constructed Wetlands. To date, little is known about bacterial community structures in the free water surface constructed wetlands. Proteobacteria was the dominant bacteria of all the water and soil samples, with the relative abundance all over the $35 \%$ in phyla. The same conclusions had been confirmed in previous coastal water [18], airborne [19], and soil [20] studies, which could prove that Proteobacteria were the dominant phylum in almost all environmental samples. Microorganisms in Proteobacteria were gram-negative bacteria, and a large number of nitrogen-related microorganisms were distributed in Proteobacteria [21, 22]; these may explain why the relative abundances of Proteobacteria in constructed wetlands were higher than those in natural wetlands [23-25]. Bacteroidetes and Firmicutes both belonged to the gut microorganisms $[26,27]$, and the high relative abundances in this study may be due to the relatively open characteristics of the constructed wetlands, and there were a large number of birds and insects inhabiting the surrounding area, at the same time, Firmicutes were able to degrade a variety of organic pollutants [28], and the sewage treatment systems were their main source, which may explain why the relative abundances of Firmicutes in influent were higher than those in other three samples. Chloroflexi was proved to be a common phylum in various wastewaters from constructed wetland systems [29, 30]; however, in this study, the relative abundances of Chloroflexi in soil were significantly higher than those in water, so this was speculated that some microorganisms would be enriched in the soil, perhaps the same conclusions could be also summarized in Acidobacteria, Ignavibacteriae, Gemmatimonadetes, and Nitrospirae. Currently, numerous studies had found that toxigenic Cyanobacteria $[31,32]$ and the high content of Cyanobacteria in the effluent should cause the attention of the monitoring department. In this study, three bacterial phyla were emerged only in the water, while four existed only in the soil, indicating that even if the sampling locations were similar, different environmental sample sources would still cause different bacterial community structures.

The dominant bacteria found in study were basically consistent with previous studies. A small amount of Steroidobacter, a microcystin-degrading Gammaproteobacterium isolated from soil [33], was found in influent in this study, guessing it might come from the sewage treatment process. Taibaiella was the dominant genera in the biofilms [34] and soil [35]; interestingly, it was not found in influent. Sulfuricaulis was mainly isolated from sediment of a lake in Japan [36]; however, it was only exited in soil in this study. Desulfobulbus was isolated from marine sediment [37] and also only in soil, fit in with the characteristics of the sampling location geographical environment, adjacent to the ocean. In recent years, there had been very little related research on Alkaliphilus, but its abundance in influent was as high as $20.67 \%$, which needed our more attentions. Limnohabitans, novel planktonic Betaproteobacteria, isolated from a freshwater reservoir, could prove that the quality of water across constructed wetlands had improved significantly. Calothrix is the dominant flora in natural water [38], and the relative abundances increased significantly after purification.

This study found that the soil community diversities were lower than those of the water, while the dry soil bacterial 
structures were simpler than wet soil. Mycobacterium is an important global threat to individuals with cystic fibrosis [39], and the relative abundances in water were much higher than those in soil in this study, reduced substantially through the water treatment, which had been confirmed to be correlated with turbidity [40]. Enterococcus showed high cholesterol removal ability [41] and were capable of hydrogen production [42], which could lay the foundation for researches on new energy. Dysgonomonas could cause liver abscesses [43] and played a major role in the mechanism for electricity generation [44], which were found only in water. Flavobacterium caused devastating mortality in various freshwater fish species globally [45] and were isolated from the China No. 1 glacier, as a kind of psychrophilic bacteria [46]. Pseudomonas was responsible for chronic infection [47] and was the most common bacteria in the soil [48], and this may explain why the relative abundances of Pseudomonas in dry soil sample were higher than those in water and wet soil samples. Janthinobacterium may cause a soft rot disease of Agaricus bisporus [49] and were isolated from both water [50] and soil [51]; however, there were no such genus in the soil samples of this study.

4.2. Archaeal Diversity and Community of Soil and Water in Constructed Wetlands. The distributions of archaeal abundance in water and soil in constructed wetlands were poorly understood, which increased difficulty in the analysis of this study. Among them, 1.03\% 9.07\% of the sequences could not find its chimera, and $0.14 \% \sim 2.07 \%$ was identified as bacteria. Three archaeal phyla was found in this study, but the gap between water and soil was very large. Euryarchaeotic, accounting for $93.29 \%$, were the dominant phylum in influent, which is involved in methane production [52]. At present, in the constructed wetland system, there were only a few related researches which revealed that Euryarchaeotic was an advantage phylum [53, 54]. In this study, it had reached as much as $93.29 \%$, which should arouse our attention. Most previous studies suggested that Euryarchaeotic was a major archaeal group in constructed wetland system $[55,56]$, but the influential factors, which affect the relative abundance of Euryarchaeotic, were not yet clear [57]. Thaumarchaeota was a marine archaea and abundant ammoniaoxidizers [58], which ensured the purification efficiency of constructed wetlands and had been widely reported before $[59,60]$. This study also found a small amount of Crenarchaeota, which had a high abundance in a temperate acidic forest soil [61], and this conclusion was also consistent with the water quality of the constructed wetland.

Previous researches had reported Nitrososphaera and Nitrosopumilus [62, 63] belonged to ammonia-oxidation archaea, their large amount of existence could guarantee the purification effect of the constructed wetland system. The relative abundances of Nitrosopumilus increased suddenly after passing through the constructed wetlands, from $0.79 \%$ to $75.12 \%$, which may be mainly related to the concentration of dissolved oxygen. Methanomassiliicoccus, Methanosarcina, Methanomethylovorans, Methanocorpusculum, Methanobrevibacter, and Methanobacterium were all classified as methanogenic archaea had great potentials for different industrial uses [64]. The methanogenic archaeon Methanomassiliicoccus was isolated from human feces [65], and the discovery of it filled the blank of the natural coalbased methanogen group records. Methanosarcina played an important role in the long-term bioremediation of uranium-contaminated aquifers and had the potential to influence uranium geochemistry in a diversity of anaerobic sedimentary environments [66]. Methanosaeta had only been reported once in the past three years [67], and its research should be strengthened later. Methanomethylovorans was also a methylotrophic archaea and had a great potential as additional inoculum for bioreactors to carry out biogas production and other related processes [68]. Desulfurococcus was an anaerobic, hyperthermophilic crenarchaeon and able to use a variety of different carbon sources [69]. In addition to the genera mentioned above, this study could not find the previous studies on Thermodiscus, Staphylothermus, and Ignisphaera, which should be emphasized in later studies because of their high relative abundances in soil samples.

\section{Conclusion}

Taken together, the present study, using the Illumina MiSeq high-throughput sequencing method, provided a detailed picture of bacterial and archaeal community variations on phylum, classes, and genus level under the fullscale constructed wetlands. Sequencing results and alpha diversity indices indicated that the total bacterial OTUs could be assigned into 29 different phyla, while archaeal OTUs were only 3. Among them, Proteobacteria were the most dominant bacterial phyla with the relative abundance of $35.38 \% \sim 48.66 \%$. Euryarchaeotic and Thaumarchaeota were the dominant archaeal phyla. The diversity of bacterial community structure was significantly higher than that of archaea simultaneously, and the community structures of soil microorganisms were obviously different from the water microorganisms. At genus level, nine bacterial genera had close relation with animal or plant diseases, which could be used for microbial risk assessment simultaneously, and archaeal genera were mainly concentrated in methanogens or anaerobic archaea, which might provide some useful microbial information for the bioremediation. It is worth noting that the lack of researches in archaea had brought great difficulties to this study, which should be emphasized in later studies.

\section{Data Availability}

The data used to support the findings of this study are available from the corresponding author upon request.

\section{Conflicts of Interest}

The authors declare that they have no conflicts of interest.

\section{Acknowledgments}

The authors want to thank the Municipal Enterprise for Water and Sewage of Jiaonan (Qingdao, China) for the 
permission of water and soil sampling at the Municipal Wastewater Treatment Plant of Jiaonan. This work was funded by the National Natural Science Foundation of China (nos. 31570541 and 31170509), the Natural Science Foundation of Shandong Province (2015ZRB01546), the Science and Technology Plan Projects for Universities in Shandong Province (J14LD05), and Basic Research Project of Qingdao (15-9-1-64-jch).

\section{References}

[1] Y. C. Zheng, X. C. Wang, Y. Ge, M. Dzakpasu, J. Q. Xiong, and Y. Q. Zhao, "Effect of plant harvest on nutrients removal by surface-flow constructed wetland for water quality improvement," in 14th IWA International Conference on Wetland System for Pollution Control, Shanghai, China, 2014.

[2] L. V. Bao-Ping, D. W. Jia, W. X. Tian, T. XB, and J. FH, "Analysis on types and environmental and geological problems of wetlands in Shandong Province," Land and Resources in Shandong Province, vol. 4, p. 23, 2008.

[3] Y. W. Feng, K. Hou, H. Y. Pei, W. R. Hu, Y. Ren, and J. L. Wei, "Desmid community characteristics and its relationship with environmental variables in Nansi Lake and Dongping Lake," Chinese Journal of Ecology, vol. 34, no. 6, pp. 1738-1746, 2015.

[4] Z. Yang, Q. Wang, J. Zhang, H. Xie, and S. Feng, "Effect of plant harvesting on the performance of constructed wetlands during summer," Water, vol. 8, no. 1, p. 24, 2016.

[5] S. Q. Wu, J. J. Chang, Y. Dai, Z. B. Wu, and W. Liang, “Treatment performance and microorganism community structure of integrated vertical-flow constructed wetland plots for domestic wastewater," Environmental Science and Pollution Research, vol. 20, no. 6, pp. 3789-3798, 2013.

[6] J. B. Ramond, P. J. Welz, D. A. Cowan, and S. G. Burton, "Microbial community structure stability, a key parameter in monitoring the development of constructed wetland mesocosms during start-up," Research in Microbiology, vol. 163, no. 1, pp. 28-35, 2012.

[7] K. Song, S. H. Lee, and H. Kang, "Denitrification rates and community structure of denitrifying bacteria in newly constructed wetland," European Journal of Soil Biology, vol. 47, no. 1, pp. 24-29, 2011.

[8] G. Xu, Y. Han, L. Li, and J. Liu, "Characterization and source analysis of indoor/outdoor culturable airborne bacteria in a municipal wastewater treatment plant," Journal of Environmental Sciences, 2018.

[9] Y. Wan, X. Ruan, Y. Zhang, and R. Li, "Illumina sequencingbased analysis of sediment bacteria community in different trophic status freshwater lakes," Microbiologyopen, vol. 6, no. 4 , article e00450, 2017.

[10] C. Hong, Y. Si, Y. Xing, and Y. Li, "Illumina MiSeq sequencing investigation on the contrasting soil bacterial community structures in different iron mining areas," Environmental Science and Pollution Research International, vol. 22, no. 14, pp. 10788-10799, 2015.

[11] K. Kuroda, M. Hatamoto, N. Nakahara et al., "Community composition of known and uncultured archaeal lineages in anaerobic or anoxic wastewater treatment sludge," Microbial Ecology, vol. 69, no. 3, pp. 586-596, 2015.

[12] T. Magoč and S. L. Salzberg, "FLASH: fast length adjustment of short reads to improve genome assemblies," Bioinformatics, vol. 27, no. 21, pp. 2957-2963, 2011.
[13] A. Chao and M. C. K. Yang, "Stopping rules and estimation for recapture debugging with unequal failure rates," Biometrika, vol. 80, no. 1, pp. 193-201, 1993.

[14] A. Chao, "Nonparametric estimation of the number of classes in a population," Scandinavian Journal of Statistics, vol. 11, no. 4, pp. 265-270, 1984.

[15] C. E. Shannon, "A mathematical theory of communication: the bell system technical journal," Journal of the Franklin Institute, vol. 196, no. 4, pp. 519-520, 1938.

[16] E. H. Simpson, "Measurement of diversity," Nature, vol. 163, no. 4148, p. 688, 1949.

[17] R. Angel, P. Claus, and R. Conrad, "Methanogenic archaea are globally ubiquitous in aerated soils and become active under wet anoxic conditions," ISME Journal, vol. 6, no. 4, pp. 847$862,2012$.

[18] S. Rampadarath, K. Bandhoa, D. Puchooa, R. Jeewon, and S. Bal, "Early bacterial biofilm colonizers in the coastal waters of Mauritius," Electronic Journal of Biotechnology, vol. 29, pp. 13-21, 2017.

[19] R. M. Bowers, I. B. McCubbin, A. G. Hallar, and N. Fierer, "Seasonal variability in airborne bacterial communities at a high-elevation site," Atmospheric Environment, vol. 50, pp. 41-49, 2012.

[20] R. Sun, J. Jin, G. Sun, Y. Liu, and Z. Liu, "Screening and degrading characteristics and community structure of a high molecular weight polycyclic aromatic hydrocarbon-degrading bacterial consortium from contaminated soil," Journal of Environmental Sciences, vol. 22, no. 10, pp. 1576-1585, 2010.

[21] O. V. Tsoy, D. A. Ravcheev, J. Čuklina, and M. S. Gelfand, "Nitrogen fixation and molecular oxygen: comparative genomic reconstruction of transcription regulation in Alphaproteobacteria," Frontiers in Microbiology, vol. 7, no. 201, p. 1343, 2016.

[22] A. Vaksmaa, T. A. van Alen, K. F. Ettwig et al., "Stratification of diversity and activity of methanogenic and methanotrophic microorganisms in a nitrogen-fertilized Italian paddy soil," Frontiers in Microbiology, vol. 8, p. 2127, 2017.

[23] Q. Cao, H. Wang, and X. Chen, "Composition and distribution of microbial communities in natural river wetlands and corresponding constructed wetlands," Ecological Engineering, vol. 98, pp. 40-48, 2017.

[24] J. Zhang, Q. Wang, J. Fan et al., "Comparisons of microbial abundance and community among different plant species in constructed wetlands in summer," Ecological Engineering, vol. 82, pp. 376-380, 2015.

[25] Y. Guo, H. Gong, and X. Guo, "Rhizosphere bacterial community of Typha angustifolia L. and water quality in a river wetland supplied with reclaimed water," Applied Microbiology and Biotechnology, vol. 99, no. 6, pp. 2883-2893, 2015.

[26] F. Thomas, J. H. Hehemann, E. Rebuffet, M. Czjzek, and G. Michel, "Environmental and gut Bacteroidetes: the food connection," Frontiers in Microbiology, vol. 2, p. 93, 2011.

[27] G. Ramachandran, A. Miguel-Arribas, D. Abia et al., "Discovery of a new family of relaxases in Firmicutes bacteria," PloS Genetics, vol. 13, no. 2, article e1006586, 2017.

[28] B. Nogales, E. R. B. Moore, W. R. Abraham, and K. N. Timmis, "Identification of the metabolically active members of a bacterial community in a polychlorinated biphenyl-polluted moorland soil," Environmental Microbiology, vol. 1, no. 3, pp. 199-212, 1999. 
[29] L. Yang and C.C. Hu, "Treatments of oil-refinery and steelmill wastewaters by mesocosm constructed wetland systems," Water Science and Technology, vol. 51, no. 9, p. 157, 2005.

[30] G. Ansola, P. Arroyo, and L. E. Sáenz de Miera, "Characterisation of the soil bacterial community structure and composition of natural and constructed wetlands," Science of the Total Environment, vol. 473-474, no. 3, pp. 63-71, 2014.

[31] B. A. Neilan, L. A. Pearson, M. C. Moffitt et al., "The genetics and genomics of cyanobacterial toxicity," in Cyanobacterial Harmful Algal Blooms: State of the Science and Research Needs, pp. 477-486, Springer New York, 2017.

[32] S. I. Sidelev, L. G. Korneva, V. V. Solovyeva, A. A. Zubishina, and D. N. Pligin, "Molecular genetic identification and seasonal succession of toxigenic cyanobacteria in phytoplankton of the Rybinsk Reservoir (Russia)," Inland Water Biology, vol. 9, no. 4, pp. 368-374, 2016.

[33] Z. L. Gong, C. F. Zhang, R. Jin, and Y. Q. Zhang, "Steroidobacter flavus sp. nov., a microcystin-degrading Gammaproteobacterium isolated from soil," Antonie Van Leeuwenhoek, vol. 109, no. 8, pp. 1073-1079, 2016.

[34] M. el-Fadel, F. Sleem, J. Hashisho, P. E. Saikaly, I. Alameddine, and S. Ghanimeh, "Impact of SRT on the performance of MBRs for the treatment of high strength landfill leachate," Waste Management, vol. 73, pp. 165-180, 2018.

[35] S. G. Szerdahelyi, Á. Szu"cs, H. G. Daood et al., "Taibaiella coffeisoli sp. nov. isolated from the soil of a coffee plantation," International Journal of Systematic and Evolutionary Microbiology, vol. 66, no. 4, pp. 1627-1632, 2016.

[36] T. Watanabe, H. Kojima, and M. Fukui, "Sulfuricaulis limicola gen. nov., sp. nov. a sulfur oxidizer isolated from a lake," International Journal of Systematic and Evolutionary Microbiology, vol. 66, no. 1, pp. 266-270, 2016.

[37] H. Kharrat, F. Karray, M. Bartoli et al., "Desulfobulbus aggregans, sp. nov. a novel sulfate reducing bacterium isolated from marine sediment from the Gulf of Gabes," Current Microbiology, vol. 74, no. 4, pp. 449-454, 2017.

[38] E. Berrendero, E. Perona, and P. Mateo, "Genetic and morphological characterization of Rivularia and Calothrix (Nostocales, Cyanobacteria) from running water," International Journal of Systematic and Evolutionary Microbiology, vol. 58, no. 2, pp. 447-460, 2008.

[39] J. M. Bryant, D. M. Grogono, D. Rodriguez-Rincon et al., "Emergence and spread of a human-transmissible multidrugresistant nontuberculous mycobacterium," Science, vol. 354, no. 6313, pp. 751-757, 2016.

[40] J. O. Falkinham, C. D. Norton, and M. W. Lechevallier, "Factors influencing numbers of Mycobacterium avium, Mycobacterium intracellulare, and other mycobacteria in drinking water distribution systems," Applied and Environmental Microbiology, vol. 67, no. 3, pp. 1225-1231, 2001.

[41] L. Guo, T. Li, Y. Tang, L. Yang, and G. Huo, "Probiotic properties of Enterococcus strains isolated from traditional naturally fermented cream in China," Microbial Biotechnology, vol. 9, no. 6, pp. 737-745, 2016.

[42] G. Stary, "Paul Pelliot (1878-1945). His life and works - a bibliography. (Indiana University oriental series, vol. IX) by Hartmut Walravens; Denis Sinor," Applied \& Environmental Microbiology, vol. 70, no. 9, pp. 5373-5382, 2004.

[43] C. H. Chen, S. S. Wu, and R. H. Hsiu, "Dysgonomonas capnocytophagoides bacteremia due to liver abscesses after radiofrequency ablation in a patient with hepatocellular carcinoma,"
Journal of the Formosan Medical Association, vol. 115, no. 10 , pp. $889-890,2016$.

[44] K. Watanabe, M. Miyahara, T. Shimoyama, and K. Hashimoto, "Population dynamics and current-generation mechanisms in cassette-electrode microbial fuel cells," Applied Microbiology and Biotechnology, vol. 92, no. 6, pp. 1307-1314, 2011.

[45] P. Kayansamruaj, H. T. Dong, I. Hirono, H. Kondo, S. Senapin, and C. Rodkhum, "Comparative genome analysis of fish pathogen Flavobacterium columnare reveals extensive sequence diversity within the species," Infection, Genetics and Evolution, vol. 54, pp. 7-17, 2017.

[46] F. Zhu, S. Wang, and P. Zhou, "Flavobacterium xinjiangense sp. nov. and Flavobacterium omnivorum sp. nov., novel psychrophiles from the China No. 1 glacier," International Journal of Systematic \& Evolutionary Microbiology, vol. 53, no. 3, pp. 853-857, 2003.

[47] D. Araújo, M. Shteinberg, S. Aliberti et al., "The independent contribution of Pseudomonas aeruginosa infection to longterm clinical outcomes in bronchiectasis," European Respiratory Journal, vol. 51, no. 2, article 1701953, 2018.

[48] R. E. Ingham, J. A. Trofymow, E. R. Ingham, and D. C. Coleman, "Interactions of bacteria, fungi, and their nematode grazers: effects on nutrient cycling and plant growth," Ecological Monographs, vol. 55, no. 1, pp. 119-140, 1985.

[49] S. P. Lincoln, T. R. Fermor, and B. J. Tindall, "Janthinobacterium agaricidamnosum sp. nov., a soft rot pathogen of Agaricus bisporus," International Journal of Systematic Bacteriology, vol. 49, no. 4, pp. 1577-1589, 1999.

[50] X. Gong, S. Skrivergaard, B. S. Korsgaard et al., "High quality draft genome sequence of Janthinobacterium psychrotolerans sp. nov. isolated from a frozen freshwater pond," Standards in Genomic Sciences, vol. 12, no. 1, p. 8, 2017.

[51] P. D. Schloss, H. K. Allen, A. K. Klimowicz et al., "Psychrotrophic strain of Janthinobacterium lividum from a cold Alaskan soil produces prodigiosin," DNA and Cell Biology, vol. 29, no. 9, pp. 533-541, 2010.

[52] A. Hu, L. Hou, and C. P. Yu, "Biogeography of planktonic and benthic archaeal communities in a subtropical eutrophic estuary of China," Microbial Ecology, vol. 70, no. 2, pp. 322-335, 2015.

[53] T. He, W. Guan, Z. Luan, and S. Xie, "Spatiotemporal variation of bacterial and archaeal communities in a pilot-scale constructed wetland for surface water treatment," Applied Microbiology and Biotechnology, vol. 100, no. 3, pp. 1479-1488, 2016.

[54] Y. Liu, H. Li, Q. F. Liu, and Y. H. Li, "Archaeal communities associated with roots of the common reed (Phragmites australis) in Beijing Cuihu wetland," World Journal of Microbiology and Biotechnology, vol. 31, no. 5, pp. 823-832, 2015.

[55] M. Bouali, I. Zrafi, A. Bakhrouf, S. Chaussonnerie, and A. Sghir, "Bacterial structure and spatiotemporal distribution in a horizontal subsurface flow constructed wetland," Science of the Total Environment, vol. 98, no. 7, pp. 3191-3203, 2014.

[56] M. Bouali, E. Pelletier, S. Chaussonnerie, D. le Paslier, A. Bakhrouf, and A. Sghir, "Characterization of rhizosphere prokaryotic diversity in a horizontal subsurface flow constructed wetland using a PCR cloning-sequencing based approach," Applied Microbiology and Biotechnology, vol. 97, no. 9, pp. 4221-4231, 2013.

[57] Y. Long, H. Yi, S. Chen et al., "Influences of plant type on bacterial and archaeal communities in constructed wetland 
treating polluted river water," Environmental Science \& Pollution Research, vol. 23, no. 19, pp. 19570-19579, 2016.

[58] N. A. Ahlgren, Y. Chen, D. M. Needham et al., "Genome and epigenome of a novel marine Thaumarchaeota strain suggest viral infection, phosphorothioation DNA modification, and multiple restriction systems," Environmental Microbiology, vol. 19, no. 6, pp. 2434-2452, 2017.

[59] Y. Zou, G. Zhu, X. Feng, C. Xia, and L. Zhou, "Enhanced ammonium-n removal in a constructed wetland and the microbial mechanisms of ammonia-oxidization at low temperature," Acta Scientiae Circumstantiae, vol. 34, no. 4, pp. 864-871, 2014.

[60] Y. Liu, J. Zhang, L. Zhao, Y. Li, Y. Dai, and S. Xie, "Distribution of sediment ammonia-oxidizing microorganisms in plateau freshwater lakes," Applied Microbiology and Biotechnology, vol. 99, no. 10, pp. 4435-4444, 2015.

[61] J. E. Lima-Perim, E. M. Romagnoli, F. Dini-Andreote, A. Durrer, A. C. F. Dias, and F. D. Andreote, "Linking the composition of bacterial and archaeal communities to characteristics of soil and flora composition in the Atlantic rainforest," PLoS One, vol. 11, no. 1, article e0146566, 2016.

[62] G. Feng, W. Sun, F. Zhang, L. Karthik, and Z. Li, "Inhabitancy of active Nitrosopumilus-like ammonia-oxidizing archaea and Nitrospira nitrite-oxidizing bacteria in the sponge Theonella swinhoei," Scientific Reports, vol. 6, no. 1, article 24966, 2016.

[63] D. Gang, W. Qi, H. Liu, and J. Qu, “The impact of water level change on the abundance and diversity of ammonia oxidizing bacteria $(\mathrm{AOB})$ and ammonia oxidizing archaea (AOA) in water-fluctuating zone," Huanjing Kexue Xuebao, vol. 37, no. 5, pp. 1615-1622, 2017.

[64] Y. Q. Wei, R. J. Long, H. Yang et al., "Fiber degradation potential of natural co-cultures of Neocallimastix frontalis and Methanobrevibacter ruminantium isolated from yaks (Bos grunniens) grazing on the Qinghai Tibetan Plateau," Anaerobe, vol. 39, pp. 158-164, 2016.

[65] C. Bang, T. Vierbuchen, T. Gutsmann, H. Heine, and R. A. Schmitz, "Immunogenic properties of the human gutassociated archaeon Methanomassiliicoccus luminyensis and its susceptibility to antimicrobial peptides," PLoS One, vol. 12, no. 10, article e0185919, 2017.

[66] D. E. Holmes, R. Orelana, L. Giloteaux et al., "Potential for Methanosarcina to contribute to uranium reduction during acetate-promoted groundwater bioremediation," Microbial Ecology, 2018.

[67] T. Koo, S. G. Shin, J. Lee et al., "Identifying methanogen community structures and their correlations with performance parameters in four full-scale anaerobic sludge digesters," Bioresource Technology, vol. 228, pp. 368-373, 2017.

[68] M. Cerrillo, L. Morey, M. Viñas, and A. Bonmatí, “Assessment of active methanogenic archaea in a methanol-fed upflow anaerobic sludge blanket reactor," Applied Microbiology and Biotechnology, vol. 100, no. 23, pp. 10137-10146, 2016.

[69] D. Susanti, E. F. Johnson, A. Lapidus et al., "Permanent draft genome sequence of Desulfurococcus mobilis type strain DSM 2161, a thermoacidophilic sulfur-reducing crenarchaeon isolated from acidic hot springs of Hveravellir, Iceland," Standards in Genomic Sciences, vol. 11, no. 1, p. 3, 2016. 


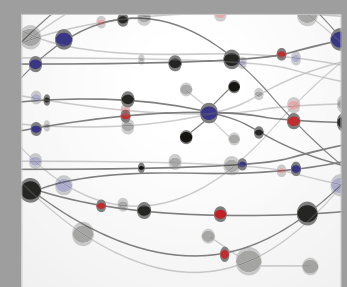

The Scientific World Journal
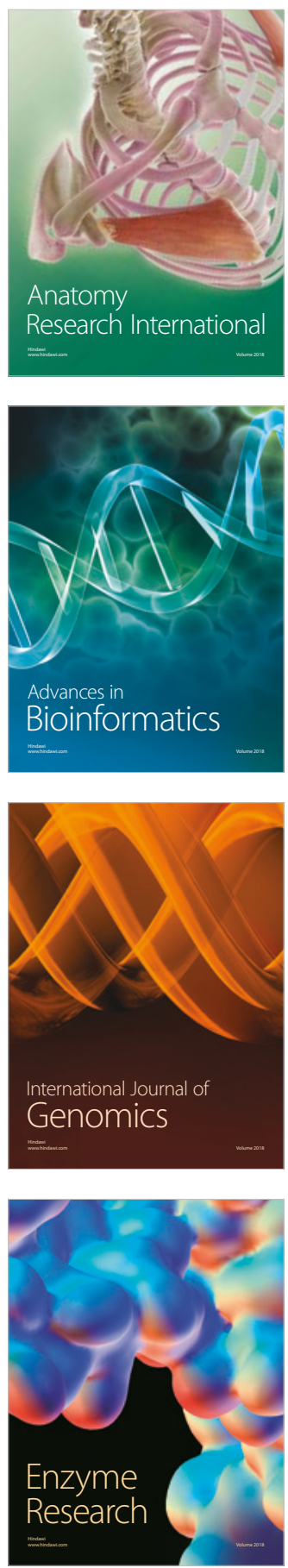
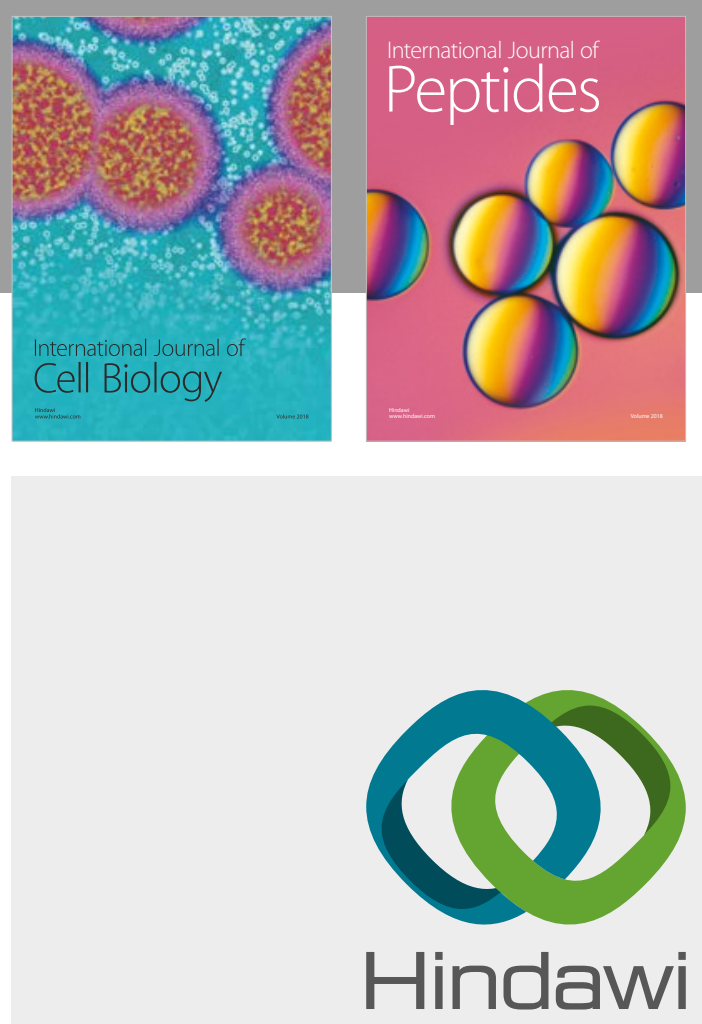

Submit your manuscripts at

www.hindawi.com
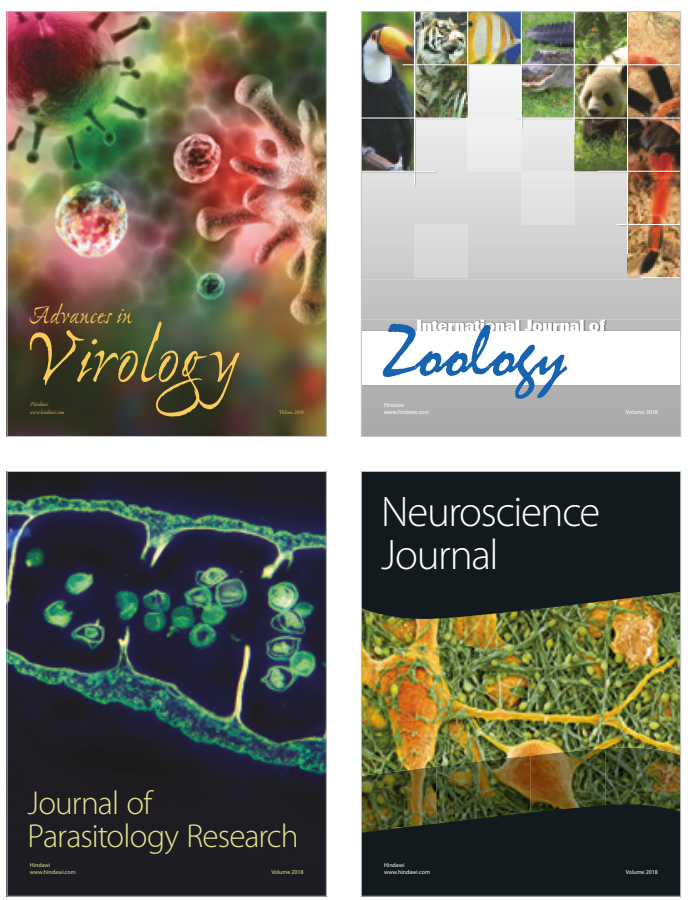
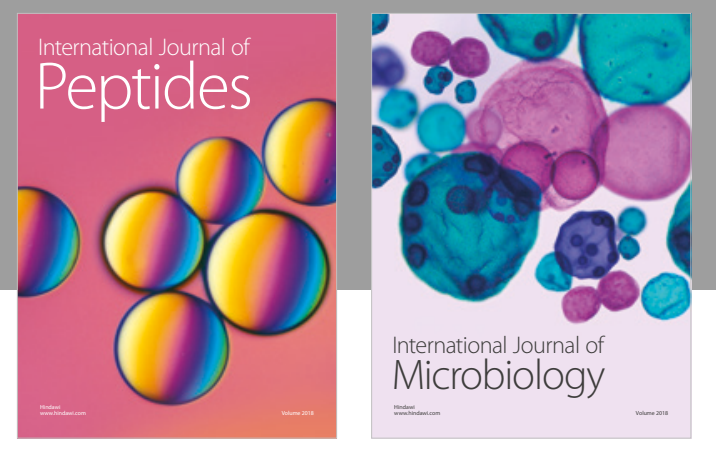

nternational Journal of Microbiology
Journal of
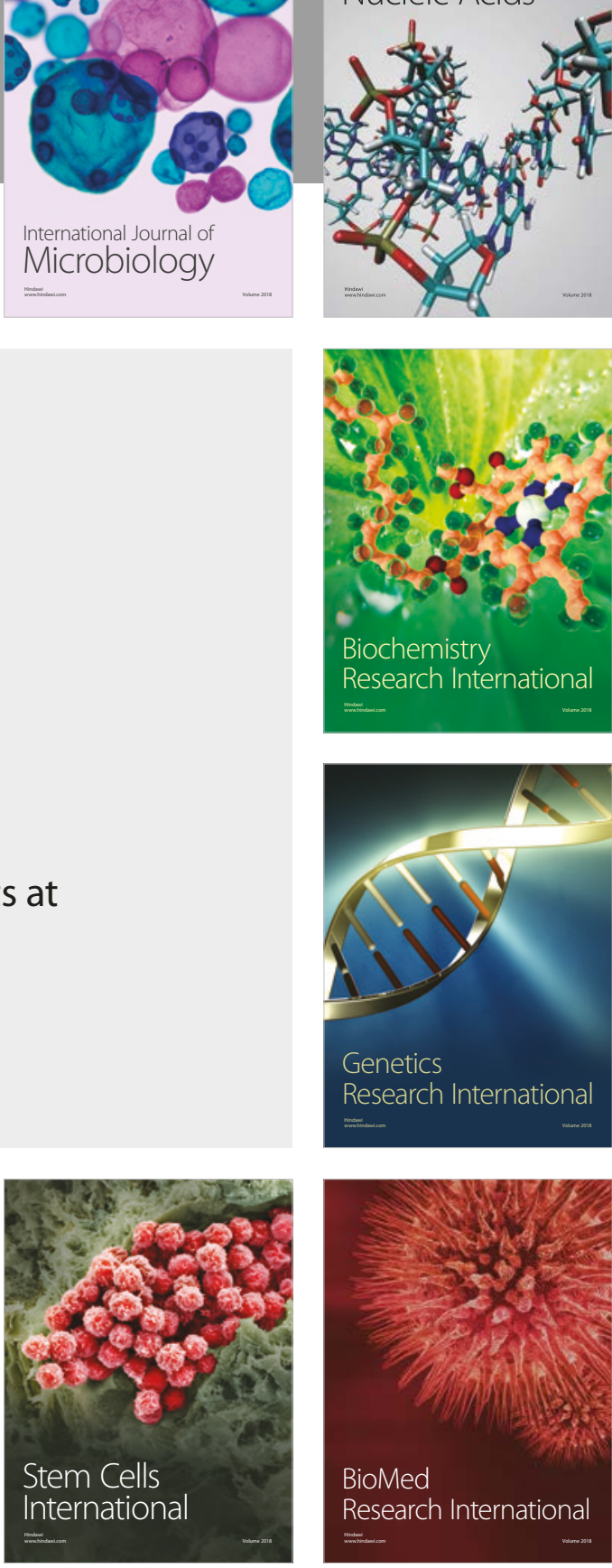
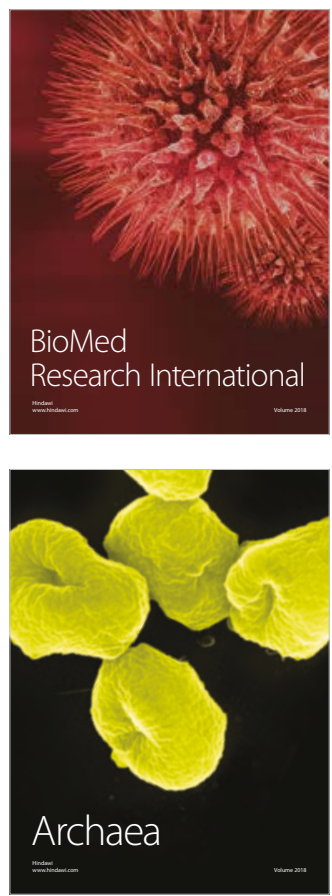